Special Article

\title{
NEIGHBORHOOD OF RESIDENCE AND INCIDENCE OF CORONARY HEART DISEASE
}

\author{
Ana V. Diez Roux, M.D., Ph.D., Sharon Stein Merkin, M.H.S., Donna Arnett, Ph.D., Lloyd Chambless, Ph.D., \\ Mark Massing, M.D., Ph.D., F. Javier Nieto, M.D., Ph.D., Paul Sorlie, Ph.D., Moyses Szklo, M.D., Dr.P.H., \\ Herman A. Tyroler, M.D., and Robert L. Watson, Ph.D.
}

\begin{abstract}
Background Where a person lives is not usually thought of as an independent predictor of his or her health, although physical and social features of places of residence may affect health and health-related behavior.

Methods Using data from the Atherosclerosis Risk in Communities Study, we examined the relation between characteristics of neighborhoods and the incidence of coronary heart disease. Participants were 45 to 64 years of age at base line and were sampled from four study sites in the United States: Forsyth County, North Carolina; Jackson, Mississippi; the northwestern suburbs of Minneapolis; and Washington County, Maryland. As proxies for neighborhoods, we used block groups containing an average of 1000 people, as defined by the U.S. Census. We constructed a summary score for the socioeconomic environment of each neighborhood that included information about wealth and income, education, and occupation.
\end{abstract}

Results During a median of 9.1 years of follow-up, 615 coronary events occurred in 13,009 participants. Residents of disadvantaged neighborhoods (those with lower summary scores) had a higher risk of disease than residents of advantaged neighborhoods, even after we controlled for personal income, education, and occupation. Hazard ratios for coronary heart disease among low-income persons living in the most disadvantaged neighborhoods, as compared with high-income persons in the most advantaged neighborhoods, were 3.1 among whites (95 percent confidence interval, 2.1 to 4.8 ) and 2.5 among blacks (95 percent confidence interval, 1.4 to 4.5 ). These associations remained unchanged after adjustment for established risk factors for coronary heart disease.

Conclusions Even after controlling for personal income, education, and occupation, we found that living in a disadvantaged neighborhood is associated with an increased incidence of coronary heart disease. (N Engl J Med 2001;345:99-106.)

Copyright $\odot 2001$ Massachusetts Medical Society.
ODAY, where a person lives is not usually thought of as an important predictor of his or her health. Lifestyle and genetic explanations for the causes of disease predominate. Nevertheless, the neighborhoods where people live may differ in many aspects potentially related to health. ${ }^{1-3}$ The socioeconomic environment of neighborhoods has been shown to be related to health status and mortality ${ }^{4-9}$ as well as to health-related behavior such as smoking, dietary habits, and physical activity.10-14 The relation between the characteristics of a neighborhood and health outcomes appears to be independent of the socioeconomic position of individual persons. ${ }^{4-14}$ This suggests that attributes of neighborhoods themselves may be important to health.

A variety of characteristics of neighborhoods, including the availability of resources and services to promote or maintain healthy lifestyles as well as the physical and social environment, may be related to cardiovascular risk. Although studies have suggested that neighborhood characteristics may be related to the prevalence of, risk factors for, and mortality due to coronary heart disease, ${ }^{8,9,13-15}$ the extent to which neighborhood characteristics are related to the incidence of coronary heart disease has not been established. We examined the relation of neighborhood characteristics to the incidence of coronary heart disease (indicated by the occurrence of coronary events) among men and women in four diverse regions of the United States.

\section{METHODS}

\section{Study Population and Study Variables}

The Atherosclerosis Risk in Communities Study is a prospective investigation of atherosclerosis in four U.S. communities:

From the Division of General Medicine, Columbia College of Physicians and Surgeons (A.V.D.R., S.S.M.), and the Division of Epidemiology, Joseph T. Mailman School of Public Health (A.V.D.R.), Columbia University, New York; the Division of Epidemiology, School of Public Health, University of Minnesota, Minneapolis (D.A.); the Department of Biostatistics and Collaborative Studies Coordinating Center (L.C.) and the Department of Epidemiology (M.M., H.A.T.), University of North Carolina at Chapel Hill, Chapel Hill; the Department of Epidemiology, Johns Hopkins University School of Hygiene and Public Health, Baltimore (F.J.N., M.S.); the Division of Epidemiology and Clinical Applications, National Heart, Lung, and Blood Institute, Bethesda, Md. (P.S.); and the Department of Preventive Medicine, University of Mississippi Medical Center, Jackson (R.L.W.) Address reprint requests to Dr. Diez Roux at the Division of General Medicine, Columbia Presbyterian Medical Center, 622 W. 168th St., PH9 E., Rm. 105, New York, NY 10032, or at ad290@columbia.edu. 
Forsyth County, North Carolina; Jackson, Mississippi; the northwestern suburbs of Minneapolis; and Washington County, Maryland. The cohort was composed of 15,792 persons 45 to 64 years of age at base line who were selected by probability sampling. ${ }^{16}$ Virtually all of the subjects from Washington County and the suburbs of Minneapolis were white. Eighty-five percent of the subjects from Forsyth County were white. All of the subjects from Jackson were black. The base-line examination took place between 1987 and 1989. Follow-up examinations were carried out every three years, and participants were contacted annually by telephone between visits to the clinic.

Participants were linked to their neighborhood of residence by their home address at base line. Census-block groups, which are subdivisions of U.S. Census tracts containing an average of 1000 people, ${ }^{17}$ were used as proxies for neighborhoods. A summary neighborhood score was used as the main indicator of the socioeconomic environment of the neighborhood.

The variables used in the construction of the neighborhood score were selected on the basis of factor analyses of data from censusblock groups. Factor analysis is a statistical technique that can be used to determine which variables out of a large set (for example, out of a large set of socioeconomic indicators obtained from the Census) can be meaningfully combined into a summary score. Six variables representing the dimensions of wealth and income (log of the median household income; log of the median value of housing units; and the percentage of households receiving interest, dividend, or net rental income), education (the percentage of adults 25 years of age or older who had completed high school and the percentage of adults 25 years of age or older who had completed college), and occupation (the percentage of employed persons 16 years of age or older in executive, managerial, or professional specialty occupations) were combined into the neighborhood summary score. For each variable, a z score for each block group was estimated by subtracting the overall mean (across all block groups in the sample) and dividing by the standard deviation. The z score reflects the deviation of the value from the mean. For example, a score of 2.0 for the $\log$ of the median household income for a given block group means that the value for that block group is $2 \mathrm{SD}$ above the overall mean; a value of -2.0 is $2 \mathrm{SD}$ below the mean. The neighborhood summary score was constructed by summing the $\mathrm{z}$ scores for each of the six variables. For example, if $\mathrm{z}$ scores for the six variables for a given block group were 1.0, 1.5, 1.8, 2.0, 1.9, and 1.8 , then the neighborhood score for that block group would be 10.0. Neighborhood scores for block groups in the sample ranged from -11.3 to 14.4 , with an increasing score signifying an increasing neighborhood socioeconomic advantage.

Subjects of each race were divided into three roughly equal groups according to the summary socioeconomic scores for their neighborhoods. Neighborhood characteristics for these groups are shown in Table 1. Over 80 percent of the members of the cohort continued to live in the same block group six years after base line. For those who had moved, correlations between base-line and follow-up measures of the neighborhood score and its components were in the range of 0.4 to 0.6 .

Information on personal income, education, and occupation was obtained from each member of the cohort during the base-line interview. Participants selected their total combined family income from eight categories (under $\$ 5,000 ; \$ 5,000$ to $\$ 7,999 ; \$ 8,000$ to $\$ 11,999 ; \$ 12,000$ to $\$ 15,999 ; \$ 16,000$ to $\$ 24,999 ; \$ 25,000$ to $\$ 34,999 ; \$ 35,000$ to $\$ 49,999$; and $\$ 50,000$ or more). Approximately 6 percent of study participants did not provide information on income, and their data were coded as a separate category. The level of education attained was classified as high school not completed, high school or general equivalency diploma completed, one to three years of college, four years of college completed, and some graduate or professional school. Information on the current or most recent occupation was collected for employed, unemployed, and retired participants. Occupations were coded according to the criteria of the 1980 U.S. Census and categorized according to six occupational groups: executive, managerial, and professional; technical, sales, and administrative support; service; farming, forestry, and fishing and precision production, craft, and repair; operators, fabricators, and laborers; and homemakers. ${ }^{18}$ Information on income was updated at the six-year follow-up examination.

Coronary events were ascertained by contacting participants annually by telephone, by conducting follow-up examinations, and by surveying discharge lists from local hospitals and death certificates from state vital-statistics offices. ${ }^{16,19,20}$ Data from all hospitalizations were abstracted according to standard criteria. Death certificates were obtained, and for most deaths that did not occur

Table 1. Neighborhood Characteristics in 1990 According to RaCe-Specific Groups of Neighborhoods Defined According to Summary Socioeconomic Scores. *

Characteristic

No. of study participants

No. of neighborhoods

Median neighborhood score

Median household income $(\$) \dagger$

Median value of housing units $(\$) \dagger$

Households with interest, dividend, or rental income $(\%)$

Adult residents who completed high school (\%)

Adult residents who completed college (\%)

Employed residents with executive, managerial, or professional occupations (\%)

\begin{tabular}{ccc}
\multicolumn{3}{c}{ WHITES } \\
\hline LOWEST \\
$\begin{array}{c}\text { MIDDLE } \\
\text { (sCRE, }-10.7 \\
\text { TO 0.7) }\end{array}$ & $\begin{array}{c}\text { HIGHEST } \\
\text { (SCORE, 0.8 }\end{array}$ & $\begin{array}{c}\text { (SCORE, } 3.8 \\
\text { TO } 14.5)\end{array}$ \\
3,085 & 3,148 & 3,209 \\
137 & 126 & 126 \\
-0.8 & 2.2 & 5.8 \\
29,100 & 36,500 & 47,200 \\
70,900 & 85,600 & 103,100 \\
36 & 50 & 62 \\
70 & 84 & 93 \\
9 & 18 & 38 \\
16 & 27 & 41
\end{tabular}

\begin{tabular}{ccc}
\multicolumn{3}{c}{ BLACKS } \\
\hline LOWEST & MIDDLE & HIGHEST \\
$($ sCORE, -11.3 & $($ sCORE, -5.9 & $($ SCORE, -1.9 \\
TO -6.0$)$ & TO -2.0$)$ & TO 9.8$)$ \\
1,247 & 1,150 & 1,170 \\
49 & 71 & 86 \\
-7.2 & -4.1 & 0.9 \\
11,100 & 17,200 & 30,000 \\
33,000 & 39,500 & 54,000 \\
4 & 13 & 20 \\
48 & 62 & 80 \\
7 & 14 & 30 \\
13 & 18 & 32
\end{tabular}

*The lowest group corresponds to the most disadvantaged neighborhoods, and the highest group corresponds to the most advantaged neighborhoods. The method of calculating the neighborhood score is described in the Methods section.

†Values have been rounded to the nearest $\$ 100$.

$00 \cdot \mathrm{N}$ Engl J Med, Vol. 345, No. $2 \cdot$ July 12, $2001 \cdot$ www.nejm.org 
in a hospital, additional information was obtained from the next of kin and from the physician. Coroners' and autopsy reports, when available, were used for validation.

A coronary event was defined as a validated definite or probable myocardial infarction for which the patient was hospitalized, a death due to coronary heart disease, or an unrecognized new myocardial infarction. The criteria for definite or probable myocardial infarction were based on combinations of chest pain, electrocardiographic changes, and levels of cardiac enzymes.19,20 The criteria for definite fatal coronary heart disease were based on chest pain, the underlying cause of death on the death certificate, and other associated information from medical records. ${ }^{19,20}$ Unrecognized new myocardial infarction was defined by the appearance, between the first and subsequent examinations, of a major $\mathrm{Q}$ wave or a minor $\mathrm{Q}$ wave with ischemic ST-T changes or an infarction, as detected by computerized Novacode ${ }^{21}$ and confirmed by side-by-side visual comparison of electrocardiograms. Persons who determined the occurrence of an event were unaware of the hypothesis being investigated. Events that occurred through December 31, 1997, were included in these analyses. The median follow-up was 9.1 years, and the maximal follow-up was 11.1 years.

For each participant, information on cardiovascular risk factors (smoking status, the level of physical activity, diet, plasma levels of low-density and high-density lipoprotein cholesterol, the presence or absence of hypertension, body-mass index [the weight in kilograms divided by the square of the height in meters], and the presence or absence of diabetes) was obtained from the base-line examination as described elsewhere. ${ }^{16}$ The level of physical activity was summarized in three indexes corresponding to leisure, sport, and work. ${ }^{22}$ The dietary intake of saturated fat, polyunsaturated fat, and cholesterol was summarized with the use of the Keys score. ${ }^{23}$ Persons were classified as having diabetes if they had fasting plasma glucose levels of $126 \mathrm{mg}$ per deciliter or more, if they had nonfasting plasma glucose levels of $200 \mathrm{mg}$ per deciliter or more, or if they reported having diabetes. Persons were classified as having hypertension if they had a systolic blood pressure of $140 \mathrm{~mm} \mathrm{Hg}$ or more, if they had a diastolic blood pressure of $90 \mathrm{~mm} \mathrm{Hg}$ or more, or if they were taking antihypertensive medication. Information on smoking, blood lipids, body-mass index, hypertension, and diabetes was also obtained at the three-year and six-year follow-up examinations. Information on diet and physical activity was updated at the six-year follow-up examination.

Of the 15,792 participants at base line, 14,158 were linked to block-group data. Ninety-eight participants who were neither white nor black or who were black and living in the suburbs of Minneapolis or in Washington County were excluded, because small numbers made analyses for these groups unreliable. Fifty-seven participants were excluded because information on education, information on occupation, or follow-up information was unavailable. After the exclusion of 994 participants with preexisting coronary heart disease (electrocardiographic signs of a previous myocardial infarction or a history of physician-diagnosed myocardial infarction, coronary heart surgery, or balloon angioplasty) or unknown disease status at base line, 13,009 participants in 595 block groups (with a median of 16 participants per block group) were available for analysis. Adjusted analyses of risk factors at base line were limited to 12,243 participants because of missing data on risk factors. The study was approved by the institutional review board at each site. All participants gave written informed consent.

\section{Statistical Analysis}

Because of large differences in the distribution of neighborhood characteristics, analyses were performed separately for blacks in Jackson and Forsyth County and for whites in Washington County, Forsyth County, and the suburbs of Minneapolis. Base-line values for neighborhood characteristics and personal socioeconomic indicators were compared with the use of linear and logistic regression for participants in whom coronary heart disease did and did not develop. ${ }^{24}$ Incidence rates were calculated by dividing the number of events by the person-years of follow-up within race-specific groups of participants defined according to the neighborhood score. Incidence rates were adjusted for age at base line and for study site with the use of Poisson regression. ${ }^{25}$ Patterns were consistent across all components of the neighborhood score, so only results for the summary score are reported. Proportional-hazards regression ${ }^{26}$ was used to obtain hazard ratios for coronary heart disease according to the three groups of neighborhood scores after adjustment for personal indicators of social position (income, education, and occupation) and after additional adjustment for cardiovascular risk factors. We performed tests for trend by introducing neighborhood groups defined according to summary scores (lowest, intermediate, and highest) as ordinal variables in regressions. ${ }^{25}$

The combined effects of neighborhood characteristics and personal socioeconomic status were examined by estimating incidence rates (and hazard ratios) for nine cross-classified categories of neighborhood score and personal income. For these analyses, annual income in each racial group was categorized as less than $\$ 25,000$ (25 percent of the sample), $\$ 25,000$ to $\$ 49,999$ (43 percent), and $\$ 50,000$ or more (32 percent) for whites and as less than $\$ 8,000$ (26 percent), $\$ 8,000$ to $\$ 24,999$ (43 percent), and $\$ 25,000$ or more (31 percent) for blacks. In order to account for potential within-neighborhood correlations in outcomes, models were run with the use of SUDAAN statistical software. ${ }^{27}$ All reported P values are two-tailed.

\section{RESULTS}

A total of 615 coronary events occurred during the follow-up period in the 13,009 participants. Ageadjusted incidence rates of coronary heart disease were 7.3 per 1000 person-years among white men, 2.8 per 1000 among white women, 8.0 per 1000 among black men, and 4.5 per 1000 among black women. Participants in whom disease developed were generally more likely to live in disadvantaged neighborhoods (those with lower summary scores) than those in whom disease did not develop (Table 2). Persons in whom coronary disease developed also tended to have lower levels of income and education and were less likely to have executive, managerial, or professional occupations than those in whom coronary disease did not develop (Table 2). All risk factors investigated, such as smoking and hypertension, were generally associated with an increased incidence of coronary heart disease ( $\mathrm{da}$ ta not shown).

The incidence of coronary heart disease generally decreased with increasing neighborhood scores (Table 3). Although associations of the neighborhood score with incidence were reduced after adjustment for personal socioeconomic indicators (Table 4), differences between the most disadvantaged and the most advantaged neighborhood categories remained. Living in the most disadvantaged group of neighborhoods, as compared with the most advantaged group, was associated with a 70 to 90 percent higher risk of coronary disease in whites and a 30 to 50 percent higher risk in blacks.

Persons living in disadvantaged neighborhoods often had more unfavorable risk-factor profiles for coronary heart disease than those in more advantaged neighborhoods (data not shown). However, the differences were often small (and sometimes absent) after we controlled for personal socioeconomic indica- 


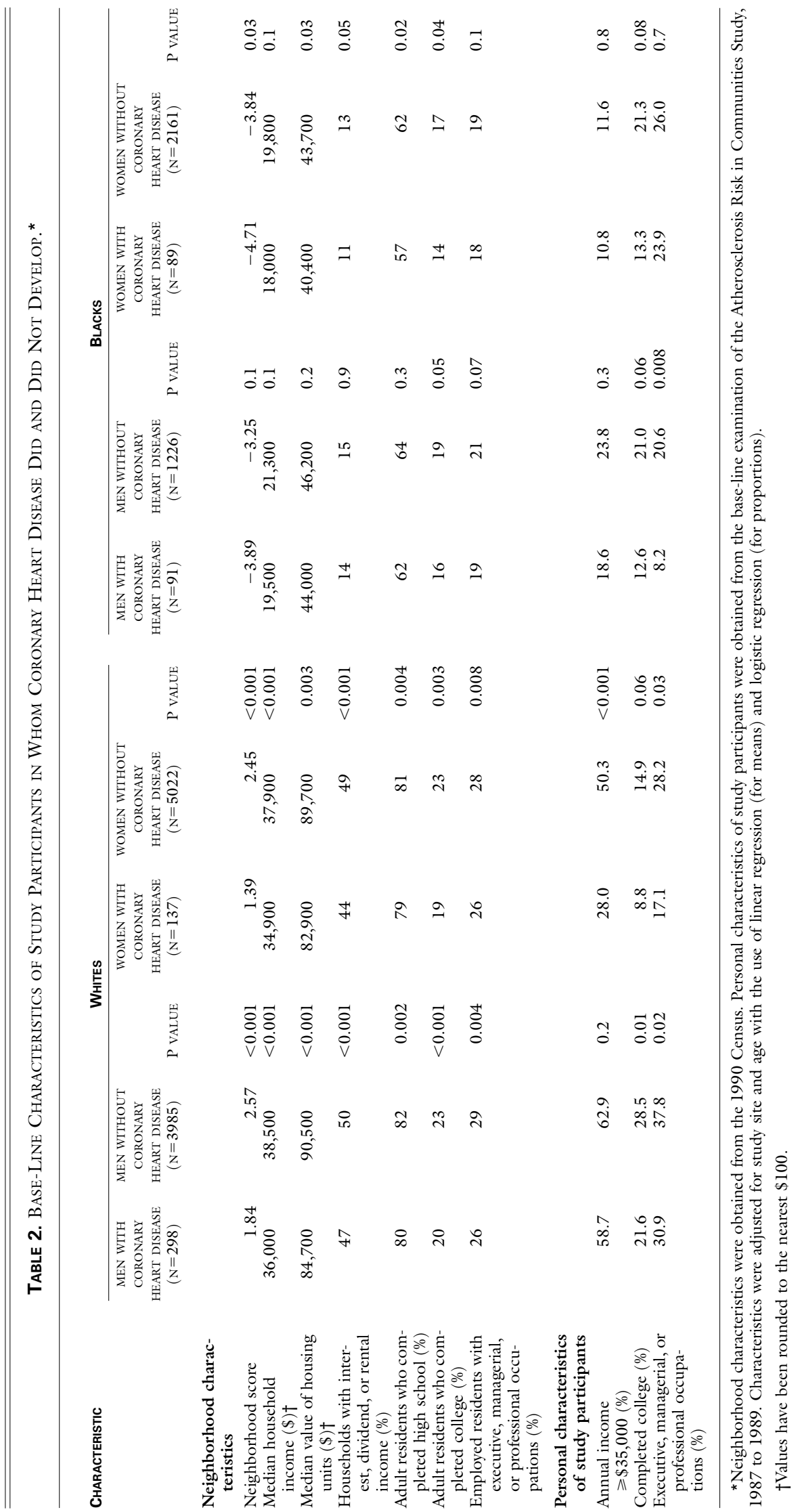

102 • N Engl J Med, Vol. 345, No. 2 • July 12, 2001 • www.nejm.org 
Table 3. InCidence of Coronary Events IN WHITES AND BLACKS.*

\begin{tabular}{|c|c|c|c|c|}
\hline \multirow[t]{3}{*}{$\begin{array}{c}\text { NeIGHBORHOOD } \\
\text { Groupt }\end{array}$} & & Men & \multicolumn{2}{|c|}{ Women } \\
\hline & & RATE PER 1000 & & RATE PER 1000 \\
\hline & $\begin{array}{l}\text { NO. OF } \\
\text { EVENTS }\end{array}$ & $\begin{array}{l}\text { PERSON-YEARS } \\
(95 \% \mathrm{CI})\end{array}$ & $\begin{array}{l}\text { NO. OF } \\
\text { EVENTS }\end{array}$ & $\begin{array}{l}\text { PERSON-YEARS } \\
(95 \% \mathrm{CI})\end{array}$ \\
\hline \multicolumn{5}{|l|}{ Whites } \\
\hline 1 (low) & 119 & $9.5(7.7-11.5)$ & 68 & $3.9(2.9-5.1)$ \\
\hline 2 & 109 & $8.3(6.8-10.0)$ & 45 & $2.6(2.0-3.6)$ \\
\hline 3 (high) & 70 & $4.9(3.8-6.3)$ & 24 & $1.5(1.0-2.3)$ \\
\hline \multicolumn{5}{|l|}{ Blacks } \\
\hline 1 (low) & 38 & $9.8(7.0-13.7)$ & 40 & $5.1(3.7-7.2)$ \\
\hline 2 & 27 & $7.5(5.1-11.0)$ & 34 & $5.1(3.6-7.2)$ \\
\hline 3 (high) & 26 & $6.4(4.3-9.4)$ & 15 & $2.7(1.6-4.5)$ \\
\hline
\end{tabular}

*Incidence rates have been adjusted for study site and age at base line in five-year categories with the use of Poisson regression. CI denotes confidence interval.

$\dagger$ Neighborhood groups correspond to three race-specific groups of neighborhoods defined according to summary socioeconomic scores. Group 1 (scores in the lowest third) corresponds to the most disadvantaged neighborhoods, and group 3 (scores in the highest third) corresponds to the most advantaged neighborhoods.

tors (which were also generally inversely associated with cardiovascular risk-factor levels). We observed more unfavorable risk profiles in more advantaged neighborhoods with respect to plasma levels of lowdensity lipoprotein and high-density lipoprotein cholesterol in black men and for the work component of the physical-activity index in white men in both unadjusted analyses and those that controlled for personal socioeconomic indicators. The addition of cardiovascular risk factors to regression models already containing personal socioeconomic indicators had little effect on the relation between neighborhood characteristics and the incidence of coronary heart disease (Table 4). We obtained similar results when we included risk factors and personal income as time-dependent covariates (data not shown).

Both neighborhood characteristics and personal income were independently associated with the incidence of coronary heart disease (Fig. 1). Overall, in whites, the neighborhood score was inversely associated with the risk of disease in all categories of personal income, and income was inversely associated with risk in all three neighborhood groups. Similar patterns were observed in blacks, but analyses were limited by small samples. Hazard ratios for coronary events for low-income persons in the group of neighborhoods with the lowest scores as compared with high-income persons in the group of neighborhoods with the highest scores were 3.1 in whites (95 percent confidence interval, 2.1 to 4.8 ) and 2.5 in blacks (95 percent confidence interval, 1.4 to 4.5 ). These patterns were similar after adjustment for changes in income between base line and the six-year follow-up examination (data not shown).

\section{DISCUSSION}

The relation between the incidence of coronary heart disease and socioeconomic factors has been documented repeatedly. ${ }^{28}$ Our findings demonstrate the additional contribution of the neighborhood of residence to the risk of coronary heart disease. Coronary heart disease was more likely to develop in persons living in the most disadvantaged group of neighborhoods than those living in the most advantaged group, even after we controlled for personal socioeconomic indicators. We minimized the possibility of residual confounding by socioeconomic position by simultaneously adjusting for income, education, and occupation, each divided into multiple categories.

Previous studies have documented geographic variations in mortality due to coronary heart disease, ${ }^{29-32}$ but the areas examined have often been large. In addition, because areas rather than individual persons were the units of analysis in these studies, it is difficult to determine whether geographic variations are due to differences among the residents of various areas or to characteristics of the areas themselves. The availability of Census data linked to personal data allowed us to examine directly whether the characteristics of smaller areas (akin to neighborhoods) are related to the risk of disease independently of the attributes of individual persons.

Neighborhood characteristics could contribute to the development and persistence of established risk factors. Thus, risk factors may be thought of as mediators (rather than confounders) of the effects of neighborhoods. Neighborhoods may differ in the amount of tobacco advertising ${ }^{33,34}$ and in the availability and cost of healthful foods. ${ }^{35-37}$ Individual behavior may, in turn, influence the neighborhood, making both factors mutually reinforcing. ${ }^{38}$ Differences among neighborhoods in the physical environment, in the availability and quality of public spaces and recreational facilities, and in perceived safety may affect patterns of physical activity. ${ }^{39,40}$ Social norms may emerge and exert their effects in neighborhoods, influencing health-related behavior. Living in various types of neighborhoods may be associated with exposure to sources of chronic stress (such as noise, violence, and poverty itself) and to sources of social support, both of which may be linked to the risk of cardiovascular disease. ${ }^{41,42}$

We did document some differences (albeit often small) among neighborhoods in established risk factors for cardiovascular disease after controlling for personal socioeconomic status. However, additional adjustment for these risk factors did not substantially alter our estimates of differences in the incidence of coronary heart disease among neighborhoods. The failure of risk factors to explain differences in the risk of car- 
Table 4. Hazard Ratios for Coronary Heart Disease According to Race-Specific Groups of Neighborhood Scores before and After Adjustment for Personal SOCiOECONOMic Indicators and Base-Line Risk Factors.

\begin{tabular}{|c|c|c|c|}
\hline \multirow[t]{2}{*}{ NeIGHBORHOOd GrouP* } & \multicolumn{3}{|c|}{ HazaRd Ratio $(95 \%$ Cl) } \\
\hline & $\begin{array}{l}\text { ADJUSTED } \\
\text { FOR AGE AND } \\
\text { STUDY SITE }\end{array}$ & $\begin{array}{l}\text { ADJUSTED FOR AGE, } \\
\text { STUDY SITE, INCOME, } \\
\text { EDUCATION, AND } \\
\text { OCCUPATION } \dagger\end{array}$ & $\begin{array}{l}\text { ADJUSTED FOR AGE, STUDY SITE, } \\
\text { INCOME, EDUCATION, OCCUPATION, } \\
\text { AND BEHAVIORAL AND } \\
\text { BIOMEDICAL RISK FACTORS } \ddagger\end{array}$ \\
\hline \multicolumn{4}{|l|}{ White men } \\
\hline $\begin{array}{l}1 \text { (low) } \\
2 \\
3 \text { (high) }\end{array}$ & $\begin{array}{l}1.9(1.4-2.7) \\
1.7(1.2-2.4) \\
1.0\end{array}$ & $\begin{array}{l}1.7(1.2-2.4) \\
1.6(1.1-2.2) \\
1.0\end{array}$ & $\begin{array}{l}1.6(1.1-2.4) \\
1.6(1.1-2.3) \\
1.0\end{array}$ \\
\hline \multicolumn{4}{|l|}{ White women } \\
\hline $\begin{array}{l}1 \text { (low) } \\
2 \\
3 \text { (high) }\end{array}$ & $\begin{array}{l}2.6(1.6-4.2) \\
1.8(1.1-2.8) \\
1.0\end{array}$ & $\begin{array}{l}1.9(1.1-3.1) \\
1.5(0.9-2.4) \\
1.0\end{array}$ & $\begin{array}{l}1.6(0.9-2.7) \\
1.4(0.9-2.3) \\
1.0\end{array}$ \\
\hline \multicolumn{4}{|l|}{ All whites $\$$} \\
\hline $\begin{array}{l}1 \text { (low) } \\
2 \text { (high) } \\
\mathrm{P} \text { value for trend }\end{array}$ & $\begin{aligned} & 2.1(1.6-2.8) \\
& 1.7(1.3-2.3) \\
& 1.0 \\
< & 0.001\end{aligned}$ & $\begin{aligned} & 1.7(1.3-2.3) \\
& 1.5(1.2-2.1) \\
& 1.0 \\
< & 0.001\end{aligned}$ & $\begin{array}{l}1.6(1.1-2.2) \\
1.5(1.1-2.0) \\
1.0 \\
0.008\end{array}$ \\
\hline \multicolumn{4}{|l|}{ Black men } \\
\hline $\begin{array}{l}1 \text { (low) } \\
2 \\
3 \text { (high) }\end{array}$ & $\begin{array}{l}1.5(0.9-2.5) \\
1.2(0.7-2.1) \\
1.0\end{array}$ & $\begin{array}{l}1.3(0.7-2.2) \\
1.0(0.5-1.9) \\
1.0\end{array}$ & $\begin{array}{l}1.4(0.8-2.5) \\
1.1(0.6-2.1) \\
1.0\end{array}$ \\
\hline \multicolumn{4}{|l|}{ Black women } \\
\hline $\begin{array}{l}1 \text { (low) } \\
2 \\
3 \text { (high) }\end{array}$ & $\begin{array}{l}1.9(1.2-3.0) \\
1.9(1.1-3.2) \\
1.0\end{array}$ & $\begin{array}{l}1.5(0.9-2.5) \\
1.7(1.0-2.9) \\
1.0\end{array}$ & $\begin{array}{l}1.8(0.9-3.4) \\
2.4(1.2-4.8) \\
1.0\end{array}$ \\
\hline \multicolumn{4}{|l|}{ All blacks $\$$} \\
\hline $\begin{array}{l}1 \text { (low) } \\
2 \\
3 \text { (high) } \\
\mathrm{P} \text { value for trend }\end{array}$ & $\begin{array}{l}1.7(1.2-2.3) \\
1.4(1.0-2.1) \\
1.0 \\
0.003\end{array}$ & $\begin{array}{l}1.4(0.9-2.0) \\
1.3(0.9-1.9) \\
1.0 \\
0.1\end{array}$ & $\begin{array}{l}1.5(1.0-2.3) \\
1.5(1.0-2.4) \\
0.09 \\
0.1\end{array}$ \\
\hline
\end{tabular}

*Neighborhood groups correspond to three race-specific groups of neighborhoods defined according to summary socioeconomic scores. Group 1 (scores in the lowest third) corresponds to the most disadvantaged neighborhoods, and group 3 (scores in the highest third) corresponds to the most advantaged neighborhoods. Group 3 served as the reference group in all comparisons.

tIncome was categorized as less than $\$ 5,000, \$ 5,000$ to $\$ 7,999, \$ 8,000$ to $\$ 11,999, \$ 12,000$ to $\$ 15,999, \$ 16,000$ to $\$ 24,999, \$ 25,000$ to $\$ 34,999, \$ 35,000$ to $\$ 49,999, \$ 50,000$ or more, or missing (6 percent of the sample). Level of education was categorized as high school not completed, high school or general equivalency diploma completed, one to three years of college completed, four years of college completed, and some graduate or professional school. Occupation was categorized as executive, managerial, and professional; technical, sales, and administrative support; service; farming, forestry, and fishing and precision production, craft, and repair; operators, fabricators and laborers; and homemakers.

$\ddagger$ Risk factors included smoking status (current, former, and never), Keys score, indexes of physical activity (leisure, sport, and work), presence or absence of hypertension, presence or absence of diabetes, serum levels of low-density lipoprotein and high-density lipoprotein cholesterol, and bodymass index. Keys score, indexes of physical activity, levels of low-density lipoprotein cholesterol, levels of high-density lipoprotein cholesterol, and body-mass index were included as continuous variables.

SInteractions between sex and neighborhood groups were not statistically significant $(\mathrm{P}=0.2$ for whites and $\mathrm{P}=0.6$ for blacks).

diovascular disease among socioeconomic groups is a common finding, even in studies focusing on traditional measures of personal income, education, and occupation (which are often strongly associated with risk factors ). ${ }^{28}$ Errors in the measurement of risk factors remain a possibility. Unaccounted-for interactions between risk factors (or between risk factors and unmeasured characteristics, such as psychosocial factors related to neighborhood characteristics) may play a part. Alternatively, mediating mechanisms that do not involve established risk factors may be involved. However, the method of investigating whether a set of factors mediates an observed effect by comparing estimates before and after adjustment has limitations. ${ }^{43}$ Therefore, we caution against concluding that the risk factors we investigated (or the interactions involving these risk factors) do not mediate any part of the differences among neighborhoods that we observed. The causal chains involved are likely to be complex.

Effects of neighborhoods were observed in both 


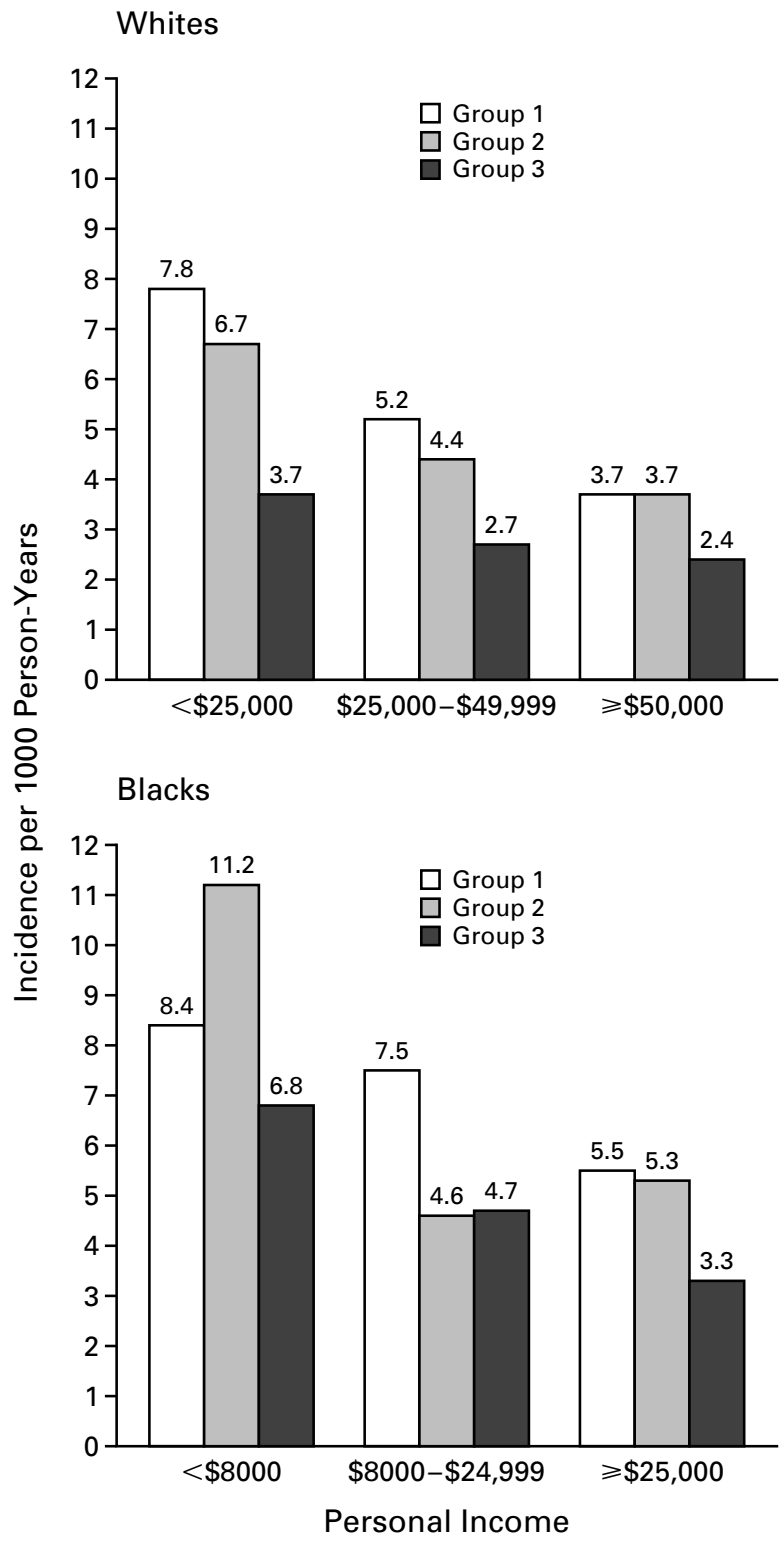

Figure 1. Incidence Rates of Coronary Heart Disease, Adjusted for Age, Study Site, and Sex According to Race-Specific Groups of Neighborhoods, Defined According to Summary Socioeconomic Scores, and According to Personal Income in Whites and Blacks.

Group 1 (scores in the lowest third) corresponds to the most disadvantaged neighborhoods, and group 3 (scores in the highest third) corresponds to the most advantaged neighborhoods.

racial groups, despite the fact that blacks were drawn from significantly more disadvantaged neighborhoods than whites - a fact that limited the range of neighborhood environments that could be examined. In previous cross-sectional analyses, we documented an unexpectedly low prevalence of coronary heart dis- ease among black men living in the most disadvantaged neighborhoods. ${ }^{13}$ This pattern was not apparent for the incidence of coronary heart disease, although associations with the neighborhood score were weaker and less consistent in blacks than in whites. These differences should be interpreted with caution, given the differences in sample size and in the range of neighborhood scores (and personal socioeconomic indicators) investigated in both groups.

Important strengths of our study include its population-based nature and the availability of detailed and validated information on coronary outcomes and risk factors. However, nearly 90 percent of the sample of black subjects was drawn from a single southern city, which may limit the generalizability of our results to blacks in other areas. Whites were drawn from three diverse regions, but the sample did not include persons living in large urban areas. Thus, our findings need to be confirmed in samples from other geographic regions. Differences in the geographic areas from which blacks and whites were drawn also limit the comparisons between races.

Another limitation of our study is the use of block groups as proxies for neighborhoods. The neighborhood socioeconomic score was used as an indirect marker of a variety of specific attributes of neighborhoods that may affect the risk of cardiovascular disease. It is striking that we observed associations even with these crude proxies. Changes over time in the neighborhood of residence may have hampered our ability to estimate the effects of neighborhoods. However, the areas of residence of the members of our cohort were relatively stable. Only 18 percent of our subjects had moved six years after the base-line examination, and for those who had moved, correlations between the base-line and follow-up measures of the neighborhood score were relatively high.

The finding that neighborhood characteristics are related to the incidence of coronary heart disease suggests that strategies for disease prevention may need to combine person-centered approaches with approaches aimed at changing residential environments. More generally, our findings point to the role of the broader social and economic forces that generate differences among neighborhoods in shaping the distribution of health outcomes. At a time of growing economic segregation of residential areas, ${ }^{44,45}$ differences among places may become even more relevant to explanations of disparities in health.

Supported by a grant (R29 HL59386, to Dr. Diez Roux) from the National Heart, Lung, and Blood Institute. The Atherosclerosis Risk in Communities Study was supported by contracts (N01-HC-55015, N01HC-55016, N01-HC-55018, N01-HC-55019, N01-HC-55020, N01-HC55021, and N01-HC-55022) with the National Heart, Lung, and Blood Institute.

We are indebted to the staff and participants in the Atherosclerosis Risk in Communities Study for their important contributions and to Dr. David Jacobs for helpful comments. 


\section{REFERENCES}

1. Kaplan G. People and places: contrasting perspectives on the association between social class and health. Int J Health Serv 1996;26:507-19.

2. Macintyre S, Maciver S, Sooman A. Area, class, and health: should we be focusing on places or people? J Soc Pol 1993;22:213-34

3. Robert S. Socioeconomic position and health: the independent contribution of community socioeconomic context. Annu Rev Sociol 1999;25: 489-516

4. Haan M, Kaplan G, Camacho T. Poverty and health: prospective evidence from the Alameda County Study. Am J Epidemiol 1987;125:989-98.

5. Anderson RT, Sorlie P, Backlund E, Johnson N, Kaplan GA. Mortality effects of community socioeconomic status. Epidemiology 1997;8:42-7.

6. Robert S. Community-level socioeconomic status effects on adult health. J Health Soc Behav 1998;39:18-37.

7. Yen IH, Kaplan G. Neighborhood social environment and risk of death: multilevel evidence from the Alameda County Study. Am J Epidemio 1999;149:898-907.

8. Smith GD, Hart C, Watt G, Hole D, Hawthorne V. Individual social class, area-based deprivation, cardiovascular disease risk factors, and mortality: the Renfrew and Paisley Study. J Epidemiol Community Health 1998; 52:399-405

9. Waitzman NJ, Smith KR. Phantom of the area: poverty-area residence and mortality in the United States. Am J Public Health 1998;88:973-6. [Erratum, Am J Public Health 1998;88:1122.]

10. Kleinschmidt I, Hills M, Elliott P. Smoking behaviour can be predicted by neighbourhood deprivation measures. J Epidemiol Community Health 1995;49:Suppl 2:S72-S77.

11. Yen IH, Kaplan GA. Poverty area residence and changes in physical activity level: evidence from the Alameda County Study. Am J Public Health 1998;88:1709-12.

12. Duncan C, Jones K, Moon G. Smoking and deprivation: are there neighbourhood effects? Soc Sci Med 1999;48:497-505

13. Diez-Roux AV, Nieto FJ, Muntaner C, et al. Neighborhood environments and coronary heart disease: a multilevel analysis. Am J Epidemiol $1997 ; 146: 48-63$

14. Diez-Roux AV, Nieto FJ, Caulfield L, Tyroler HA, Watson RL, Szklo M. Neighbourhood differences in diet: the Atherosclerosis Risk in Communities (ARIC) Study. J Epidemiol Community Health 1999;53:55-63. 15. Hart C, Ecob R, Smith GD. People, places, and coronary heart disease risk factors: a multilevel analysis of the Scottish Heart Health Study archive. Soc Sci Med 1997;45:893-902.

16. The ARIC Investigators. The Atherosclerosis Risk in Communities (ARIC) Study: design and objectives. Am J Epidemiol 1989;129:687-702. 17. Geographic areas reference manual. Washington, D.C.: Bureau of the Census, 1994

18. Bureau of the Census. 1980 Census of population: classified index of industries and occupations. Final ed. Washington, D.C.: Government Printing Office, 1982.

19. White AD, Folsom AR, Chambless LE, et al. Community surveillance of coronary heart disease in the Atherosclerosis Risk in Communities (ARIC) Study: methods and initial two years' experience. J Clin Epidemiol 1996;49:223-33

20. National Heart, Lung, and Blood Institute. Atherosclerosis Risk in Communities (ARIC) Study. Operations manual no. 3. Surveillance components procedures, version 1.0. Chapel Hill, N.C.: ARIC Coordinating Center, School of Public Health, University of North Carolina, 1987. 21. Rautaharju PM, Warren JW, Jain U, Wolf HK, Nielsen CL. Cardiac infarction injury score: an electrocardiographic coding scheme for ischemic heart disease. Circulation 1981;64:249-56.
22. Baecke JA, Burema J, Frijters JER. A short questionnaire for the meas urement of habitual physical activity in epidemiological studies. Am J Clin Nutr 1982;36:936-42.

23. Anderson JT, Jacobs DR Jr, Foster N, et al. Scoring systems for evaluating dietary pattern effect on serum cholesterol. Prev Med 1979;8:525-7. 24. Kahn HA, Sempos CT. Statistical methods in epidemiology. New

York: Oxford University Press, 1989.

25. Szklo M, Nieto FJ. Epidemiology: beyond the basics. Gaithersburg, Md.: Aspen, 2000.

26. Cox DR. Regression models and life-tables. J R Stat Soc [B] 1972;34: 187-220.

27. Shah BV, Barnwell BG, Bieler GS. SUDAAN user's manual, release 7.5. Research Triangle Park, N.C.: Research Triangle Institute, 1997.

28. Kaplan GA, Keil JE. Socioeconomic factors and cardiovascular disease: a review of the literature. Circulation 1993;88:1973-98.

29. Fabsitz R, Feinleib M. Geographic patterns in county mortality rates from cardiovascular disease. Am J Epidemiol 1980;111:315-28.

30. Elford J, Phillips AN, Thomson AG, Shaper AG. Migration and geographic variations in ischaemic heart disease in Great Britain. Lancet 1989 1:343-6.

31. Wing $S$, Dargent-Molina $P$, Casper M, Riggan W, Hayes CG, Tyroler HA. Changing association between community occupational structure and ischaemic heart disease mortality in the United States. Lancet 1987;2: 1067-70.

32. Wing S, Casper M, Riggan W, Hayes C, Tyroler HA. Socioenviron mental characteristics associated with the onset of decline of ischemic heart disease mortality in the United States. Am J Public Health 1988;78:923-6. 33. Hackbarth DP, Silvestri B, Cosper W. Tobacco and alcohol billboards in 50 Chicago neighborhoods: market segmentation to sell dangerous products to the poor. J Public Health Policy 1995;16:213-30

34. Pucci LG, Joseph HM Jr, Siegel M. Outdoor tobacco advertising in six Boston neighborhoods: evaluating youth exposure. Am J Prev Med 1998; $15: 155-9$

35. Mooney C. Cost and availability of healthy food choices in a London health district. J Hum Nutr Dietetics 1990;3:111-20.

36. Troutt D. The thin red line: how the poor still pay more. San Francisco: Consumers Union of the United States, 1993.

37. Green M. The poor pay more . . . for less. Part 1. Grocery shopping. New York: City of New York, Department of Consumer Affairs, 1991.

38. Cheadle A, Psaty BM, Curry S, et al. Community-level comparisons between the grocery store environment and individual dietary practices. Prev Med 1991;20:250-61.

39. King AC, Blair SN, Bild DE, et al. Determinants of physical activity and interventions in adults. Med Sci Sports Exerc 1992;24:Suppl:S221S236.

40. Neighborhood safety and the prevalence of physical activity - selected states, 1996. MMWR Morb Mortal Wkly Rep 1999;48:143-6.

41. Henry JP. Mechanisms by which stress can lead to coronary heart disease. Postgrad Med J 1986;62:687-93.

42. Shumaker SA, Czajkowski SM. Social support and cardiovascular dis ease. New York: Plenum Press, 1994

43. Robins JM, Greenland S. Identifiability and exchangeability for direct and indirect effects. Epidemiology 1992;3:143-55.

44. Jargowsky PA. Take the money and run: economic segregation in US metropolitan areas. Am Sociol Rev 1996;61:984-98.

45. Massey DS. The age of extremes: concentrated affluence and poverty in the twenty-first century. Demography 1996;33:395-412.

Copyright (C) 2001 Massachusetts Medical Society.

106 • N Engl J Med, Vol. 345, No. 2 • July 12, $2001 \cdot$ www.nejm.org 